\title{
Sporulation of Streptomyces venezuelae in submerged cultures
}

\author{
Mark A. Glazebrook, ${ }^{1}$ Janice L. Doull, $^{1}$ Colin Stuttard ${ }^{2}$ and Leo C. Vining ${ }^{1 *}$ \\ Departments of Biology ${ }^{1}$ and Microbiology ${ }^{2}$, Dalhousie University, Halifax, Nova Scotia B3H 4J1, Canada
}

(Received 25 July 1989; revised 19 September 1989; accepted 30 October 1989)

\begin{abstract}
Shaken cultures of Streptomyces venezuelae ISP5230 in minimal medium with galactose and ammonium sulphate as carbon and nitrogen sources, respectively, showed extensive sporulation after $72 \mathrm{~h}$ incubation at $37^{\circ} \mathrm{C}$. The spores formed in these cultures resembled aerial spores in their characteristics. The ability of the spores to withstand lysozyme treatment was used to monitor the progress of sporulation in cultures and to determine the physiological requirements for sporulation. In media containing ammonium sulphate as the nitrogen source, galactose was the best of six carbon sources tested. With galactose $S$. venezuelae ISP5230 sporulated when supplied with any of several nitrogen sources; however, an excess of nitrogen source was inhibitory. In cultures containing galactose and ammonium sulphate, sporulation was suppressed by a peptone supplement. The onset of sporulation was accompanied by a drop in intracellular GTP content. When decoyinine, an inhibitor of GMP synthase, was added to a medium containing starch and ammonium sulphate, a slight increase in sporulation was seen after $2 \mathrm{~d}$. The suppression of sporulation by peptone in liquid or agar cultures was not reversed by addition of decoyinine. A hypersporulating mutant of $S$. venezuelae ISP5230 was altered in its ability to assimilate sugars. In cultures containing glucose the mutant sporulated more profusely than did the wild-type and did not acidify the medium to the same extent. However, the suppressive effect of glucose on sporulation was not merely a secondary result of acid accumulation.
\end{abstract}

\section{Introduction}

In forming spores from filamentous mycelium, streptomycetes undergo morphological differentiation; thus they provide a useful system in which to study prokaryotic development. Until recently, however, examination of the physiological processes involved has been hampered by the apparent inability of streptomycete cultures to form spores in liquid media. Although still an infrequent event, 'submerged sporulation' has now been observed in cultures of Streptomyces griseus (Kendrick \& Ensign, 1983; Ochi, 1987; Daza et al., 1988), Streptomyces viridochromogenes (Koepsel \& Ensign, 1984), Streptomyces roseosporus (Huber et al., 1987), Streptomyces coelicolor (Koepsel \& Ensign, 1984; Daza et al., 1988) and several other species (Daza et al., 1988). A comparative analysis of spores formed in submerged cultures demonstrated that they were viable, thermoresistant and morphologically similar to aerial spores (Huber et al., 1987; Daza et al., 1988). They were also similar to surface-grown spores in their dormancy characteristics, germinability and in most cases, resistance to lysozyme treatment and to sonication (Koepsel \& Ensign, 1984).
With the exception of $S$. roseosporus cultures which formed spores in a complex medium that was not manipulated to ensure nutrient deprivation (Huber et al., 1987), the physiological condition most often associated with spore formation is a nutritional downshift. Downshifts resulted from depletion of an essential nutrient, in most cases nitrogen or phosphate (Kendrick \& Ensign, 1983; Koepsel \& Ensign, 1984; Daza et al., 1988). Sporulation of $S$. griseus in complex medium was associated with a decrease in the intracellular GTP pool. Sporulation could be suppressed by excess nutrients and the suppression was overcome by addition of decoyinine, a specific inhibitor of GMP synthetase. In a rel mutant, the decrease in the GTP pool during nutritional downshift was less pronounced, and the strain demonstrated a reduced ability to sporulate. These observations led Ochi (1986) to suggest that morphological differentiation of $S$. griseus results from a decrease in the GTP pool.

In this paper we report conditions that promote sporulation of Streptomyces venezuelae ISP5230 in submerged culture, and show that decoyinine has little effect on sporulation of this strain. We also describe the characteristics of a hypersporulating mutant. 


\section{Methods}

Strains and growth conditions. Streptomyces venezuelae ISP5230 is the wild-type strain and was obtained from E. Wellington (Stuttard, 1982). The hypersporulating strain VS601 (dev-2) was obtained by crossing VS465 with VS206 using the four-on-four procedure (Hopwood, 1967; Doull et al., 1986) and selecting from among the progeny a prototrophic, chloramphenicol-producing recombinant strain that retained the hypersporulating phenotype. Strain VS465 (dev-2 pdx-4 $\mathrm{cml}-12$ ) was isolated from $S$. venezuelae ISP5230 after mutagenesis of strain VS258 ( $p d x-4 \mathrm{cml}-12)$ with $N$-methyl- $N^{\prime}$-nitro- $N$-nitrosoguanidine (Vats, 1987). Strain VS206 (adeA10 hisA6 strA6) is a fertile derivative of $S$. venezuelae ISP5230 (Doull et al., 1986).

Vegetative mycelial suspensions used as inocula were prepared by transferring $50 \mu \mathrm{l}$ portions from a stock suspension of spores with an $\mathrm{OD}_{640}$ of 0.4 in $20 \%(\mathrm{v} / \mathrm{v})$ aqueous glycerol to $50 \mathrm{ml}$ of MYM medium (Stuttard, 1982) and incubating the culture for $24 \mathrm{~h}$ at $27^{\circ} \mathrm{C}$ on a rotary shaker $(220$ r.p.m.). Shaken cultures in which sporulation was investigated were grown from a $1 \%(\mathrm{v} / \mathrm{v})$ vegetative inoculum in 2 litre Erlenmeyer flasks, each containing $500 \mathrm{ml}$ of LS medium. This medium consisted of (w/v): MOPS, $2.1 \% ; \mathrm{K}_{2} \mathrm{HPO}_{4}, 1.05 \% ; \mathrm{KH}_{2} \mathrm{PO}_{4}$, $0.45 \%$; the salts and minerals described by Chatterjee et al. (1983); a carbon source (at $3 \%$ or $5 \%, w / v)$ and a nitrogen source (supplying $30 \mathrm{~mm}$-nitrogen). Cultures were incubated at $37^{\circ} \mathrm{C}$ on a rotary shaker (220 r.p.m.).

Sporulation agar (Ochi, 1986) consisted of (w/v): soluble starch, $2 \%$; yeast extract, $0.4 \%$ and agar $2 \%$; GYM agar differed from MYM agar (Stuttard, 1982) only in that glucose was substituted for maltose.

Chemicals. Lysozyme (grade 1) was purchased from Boehringer Mannheim; decoyinine was a gift from J. E. Grady, Upjohn Co., Kalamazoo, MI, USA.

Growth measurement. A Bausch and Lomb Spectronic 21 spectrophotometer was used to measure the $\mathrm{OD}_{640}$ of samples in round cuvettes with a $1 \mathrm{~cm}$ light path. Cultures were diluted if necessary to obtain $\mathrm{OD}_{640}$ values below 0.6 .

Sporulation assays. Samples $(1 \mathrm{ml})$ taken aseptically from cultures

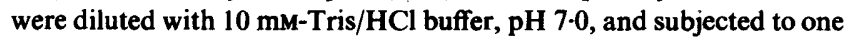
or more of the following treatments: (i) to $1 \mathrm{ml}$ of the diluted sample lysozyme $(50 \mu \mathrm{g})$ was added and the mixture was incubated at $37^{\circ} \mathrm{C}$ for 30 min to digest mycelial cell walls; (ii) the diluted sample $(9 \mathrm{ml})$ was placed in an ice-bath and mycelium was disrupted with a sonic oscillator (Branson model 200; intensity 7; six $15 \mathrm{~s}$ intervals with intervening cooling); (iii) the diluted sample ( $0.1 \mathrm{ml})$ was frozen, dried for $3 \mathrm{~h}$ under high vacuum and then resuspended in water. After treatment, the samples were plated as a dilution series on MYM agar and incubated for $24 \mathrm{~h}$ at $27^{\circ} \mathrm{C}$. The concentration of colony forming units (c.f.u.) surviving each treatment was compared with the concentration of c.f.u. in untreated culture samples similarly plated.

Analyses. Glucose and galactose concentrations in clarified culture broths were measured with the o-toluidine reagent described by Dubowski (1962).

Scanning electron microscopy. Samples were harvested from cultures by centrifugation $(2000 \mathrm{~g})$, washed (three times) and resuspended in $0.85 \% \mathrm{NaCl}$. A drop of washed sample was placed on a membrane filter (Nucleopore) and fixed for $2 \mathrm{~h}$ in a $3 \%(\mathrm{w} / \mathrm{v})$ solution of glutaraldehyde in $0.1 \mathrm{M}$-sodium cacodylate buffer, pH 7.0. After three washes with $0.1 \mathrm{M}$-sodium cacodylate, the fixed specimen was dehydrated by placing the filter sequentially for $15 \mathrm{~min}$ in $20,50,70$ and $90 \%(\mathrm{v} / \mathrm{v})$ ethanol and twice in absolute ethanol. It was then dried at the critical point, coated with platinum-gold and examined with a Baush and Lomb ARL Nanolab 2000 scanning electron microscope.
Measurement of GTP. The nucleotide pool was extracted from mycelium by the method of Ochi (1986) with the following modification : cells from $20 \mathrm{ml}$ of broth culture were rapidly collected on a $9 \mathrm{~cm}$ diameter glassfibre filter (Whatman no. 934-A11), and immediately placed upside down in a Petri dish containing $3 \mathrm{ml}$ ice-cold $1 \mathrm{M}$-formic acid. The nucleotides extracted into formic acid were analysed by HPLC as described by Ochi (1986).

\section{Results}

\section{Measurement of sporulation}

Shaken cultures of $S$. venezuelae ISP5230 in LS medium containing 5\% galactose and ammonium sulphate as the carbon and nitrogen sources formed spores abundantly after $72 \mathrm{~h}$. Like the aerial spores formed by agar cultures, these were resistant to freeze-drying, digestion with lysozyme and sonic disruption whereas mycelia were susceptible to all three treatments (Table 1). To select the most reliable and convenient method of monitoring sporulation in submerged cultures, samples collected daily were assayed for resistance to these three treatments, and were also examined by light microscopy. Both the lysozyme and freeze-drying treatments gave values for spore content that correlated well with microscopic observations, while the sonication treatment did not (Table 2). The lysozyme treatment was adopted in subsequent experiments.

\section{Effect of carbon source on sporulation}

S. venezuelae was grown in LS medium with ammonium sulphate as the nitrogen source in combination with each

Table 1. Survival $(\%)$ of aerial spores, submerged spores and mycelium during sonication, freeze-drying and treatment with lysozyme

Aerial spores were obtained from a culture grown on MYM agar for $5 \mathrm{~d}$. Sterile water was added and the spore suspension was filtered through non-absorbent cotton wool. The spores were collected by centrifugation and resuspended in sterile water to give approximately $10^{10} \mathrm{ml}^{-1}$. Submerged spores were from cultures grown for $5 \mathrm{~d}$ in LS medium with galactose and ammonium sulphate. They were collected by filtration and centrifugation as above. Mycelium was from cultures grown for $24 \mathrm{~h}$ in MYM medium (approximately $10^{8}$ c.f.u. $\mathrm{ml}^{-1}$ ). No spores were detectable in these cultures by microscopic examination. Percentage survival after treatment was estimated from the numbers of colonies obtained by plating treated and untreated samples.

\begin{tabular}{lccc}
\hline \hline & Sonication & Freeze-drying & Lysozyme \\
\hline Aerial spores & 100 & 100 & 100 \\
Submerged spores & 100 & 77 & 100 \\
Mycelium & 7 & 10 & 0 \\
\hline \hline
\end{tabular}


Table 2. Comparison of sonication, freeze-drying and lysozyme treatments for measuring sporulation in

\section{$S$. venezuelae cultures}

Cultures were grown in LS medium with $5 \%$ galactose and ammonium sulphate $\left(2 \cdot 0 \mathrm{~g} \mathrm{I}^{-1}\right)$. To estimate percentage sporulation, culture samples were diluted with buffer; one portion was plated directly on MYM agar and others were treated before plating as indicated. Percentage survival was estimated from the numbers of colonies obtained from the treated and untreated sample.

\begin{tabular}{|c|c|c|c|c|c|}
\hline \multirow[b]{2}{*}{ Day } & \multirow[b]{2}{*}{$\begin{array}{l}\text { Growth } \\
\left(O_{640}\right)\end{array}$} & \multicolumn{3}{|c|}{ Sporulation $(\%)$ after: } & \multirow[b]{2}{*}{ Microscopy* } \\
\hline & & Sonication & $\begin{array}{l}\text { Freeze- } \\
\text { drying }\end{array}$ & $\begin{array}{l}\text { Lysozyme } \\
\text { treatment }\end{array}$ & \\
\hline 1 & 0.85 & 96 & 10 & 14 & - \\
\hline 2 & $3 \cdot 2$ & 100 & 43 & 24 & + \\
\hline 3 & $4 \cdot 4$ & 100 & 45 & 61 & ++ \\
\hline 4 & $4 \cdot 8$ & 100 & 100 & 80 & +++ \\
\hline
\end{tabular}

* Samples were examined by light microscopy for the presence $(+)$ or absence $(-)$ of spores.

Table 3. Effect of carbon source on growth and sporulation of $S$. venezuelae in $L S$ medium

The medium contained ammonium sulphate $\left(2 \mathrm{gl}^{-1}\right)$ and one of the six carbon sources $(5 \%)$.

\begin{tabular}{lccc}
\hline \hline $\begin{array}{l}\text { Carbon } \\
\text { source }\end{array}$ & $\begin{array}{c}\text { Maximum } \\
\text { biomass } \\
\left(\mathrm{OD}_{640}\right)\end{array}$ & $\begin{array}{c}\text { Maximum } \\
\text { growth rate } \\
\left(\Delta \mathrm{OD}_{640} \mathbf{h}^{-1}\right)^{*}\end{array}$ & $\begin{array}{c}\text { Maximum } \\
\text { sporulation } \\
(\%) \dagger\end{array}$ \\
\hline Glucose & 1.8 & 0.075 & 4 \\
Glycerol & 3.6 & 0.06 & 32 \\
Lactose & 4.4 & 0.11 & 7 \\
Galactose & 4.8 & 0.15 & 80 \\
Maltose & 5.3 & 0.07 & 23 \\
Starch & 5.6 & 0.14 & 12 \\
\hline \hline
\end{tabular}

* Measured as the highest rate of increase in $\mathrm{OD}_{640}$ achieved during growth of the cultures.

+ Samples were assayed daily for percentage sporulation by the lysozyme procedure as in Table 2. The time of maximum sporulation varied with the carbon source used and coincided in each culture with maximum biomass (2-7 d).

of six different carbon sources at $5 \%$ concentration (Table 3). The cultures grew as well-dispersed mycelial suspensions and no wall growth was observed under any conditions used. With glucose, cultures grew poorly and sporulated sparsely. Maltose and starch supported higher biomass yields than did glucose, glycerol or lactose but sporulation did not correlate with biomass production. Thus galactose, which supported less growth than maltose or starch, promoted the highest percentage sporulation. In the cultures assimilating galactose, the percentage of spores increased as biomass accumulated

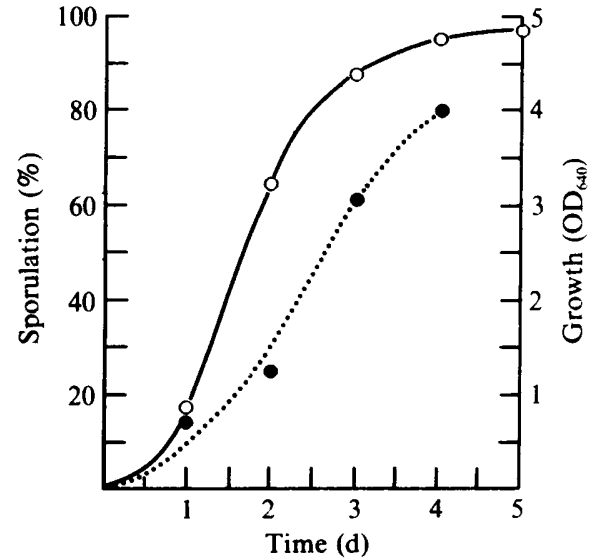

Fig. 1. Growth and sporulation of $S$. venezuelae ISP5230 in LS medium containing galactose $(5 \%)$ and ammonium sulphate $\left(2 \mathrm{~g} \mathrm{l}^{-1}\right)$. Sporulation was measured after lysozyme treatment. $O$. Growth; percentage sporulation.

(Fig. 1). Similar results were obtained when the concentration of galactose was reduced from $5 \%$ to $3 \%$.

\section{Effect of nitrogen source on sporulation}

When $S$. venezuelae was grown in LS medium with $3 \%$ galactose as the carbon source and nitrogen sources supplying $30 \mathrm{~mm}$-nitrogen, the same high level of sporulation was obtained with nitrate or asparagine as with ammonium sulphate. There was no correlation between the degree of mycelial aggregation in cultures and the number of spores estimated to be present. Cultures assimilating Casamino acids grew readily, were

Table 4. Effect of nitrogen source on growth and sporulation of $S$. venezuelae in $L S$ medium

Cultures were grown in LS medium containing galactose (3\%) and a nitrogen source supplying $30 \mathrm{~mm}$-nitrogen (for Casamino acids $0.4 \%, w / v)$. Percentage sporulation was measured by the lysozyme procedure as in Table 2.

\begin{tabular}{lccc}
\hline $\begin{array}{c}\text { Nitrogen } \\
\text { source }\end{array}$ & $\begin{array}{c}\text { Maximum } \\
\text { biomass } \\
\left(\mathrm{OD}_{640}\right)\end{array}$ & $\begin{array}{c}\text { Maximum } \\
\text { growth rate } \\
\left(\Delta \mathrm{OD}_{640} \mathrm{~h}^{-1}\right)^{*}\end{array}$ & $\begin{array}{c}\text { Maximum } \\
\text { sporulation } \\
(\%)^{*}\end{array}$ \\
\hline Isoleucine & 0.8 & 0.02 & 0 \\
Potassium nitrate & 4.7 & 0.06 & 80 \\
Ammonium sulphate & $4 \cdot 8$ & $0 \cdot 11$ & 80 \\
Asparagine & $5 \cdot 2$ & 0.09 & 83 \\
Alanine & $5 \cdot 4$ & $0 \cdot 14$ & 30 \\
Casamino acids & 5.5 & 0.12 & 66 \\
Glutamate & 6.0 & 0.08 & 37 \\
\hline \hline
\end{tabular}

* See Table 3. 

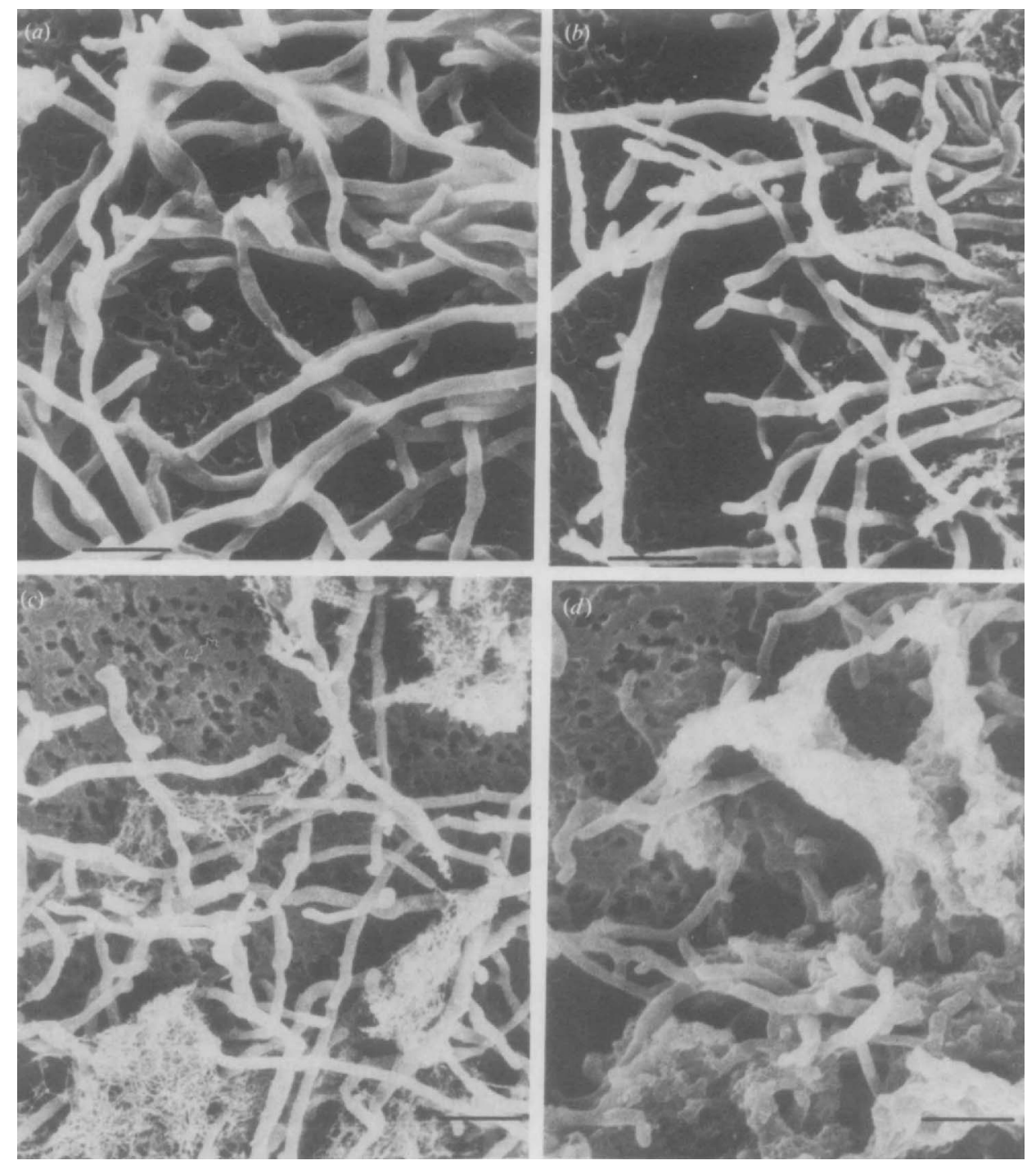

Fig. 2. Electron micrographs of $S$. venezuelae ISP5230 grown in LS medium with starch $(3 \%)$ and ammonium sulphate $\left(2 \mathrm{~g} 1^{-1}\right)$. Samples removed on days $1,2,3$ and 5 are identified as $(a)-(d)$. Bars, $4 \mu \mathrm{m}$.

Table 5. Growth and sporulation of $S$. venezuelae in $L S$ medium containing various amounts of Casamino acids

The medium contained galactose $(5 \%)$ as the carbon source. Sporulation was measured by the lysozyme procedure as in Table 2.

\begin{tabular}{ccc}
\hline \hline $\begin{array}{c}\text { Casamino acids } \\
(\%, w / v)\end{array}$ & $\begin{array}{c}\text { Maximum biomass } \\
\left(\text { OD }_{640}\right)\end{array}$ & $\begin{array}{c}\text { Maximum sporulation } \\
(\%)^{*}\end{array}$ \\
\hline 0.2 & 4.2 & 89 \\
0.4 & 5.2 & 63 \\
0.8 & 5.2 & 40 \\
1.0 & 5.3 & 0 \\
\hline \hline
\end{tabular}

* See Table 3. well-dispersed and supported good spore production, whereas those with alanine and glutamate sporulated poorly; no spores were detected in cultures with isoleucine, which showed the greatest degree of clumping (Table 4).

The effect of varying the nitrogen source concentration was examined with $3 \%$ galactose and Casamino acids in LS medium (Table 5). Increasing the concentration of Casamino acids increased the biomass yield while decreasing the extent of sporulation. With $1 \%$ Casamino acids, no spores were formed. A similar suppressive effect was also seen with asparagine; when its concentration was increased from $0.2 \%$ to $0.4 \%$, sporulation decreased from $80 \%$ to $52 \%$. 

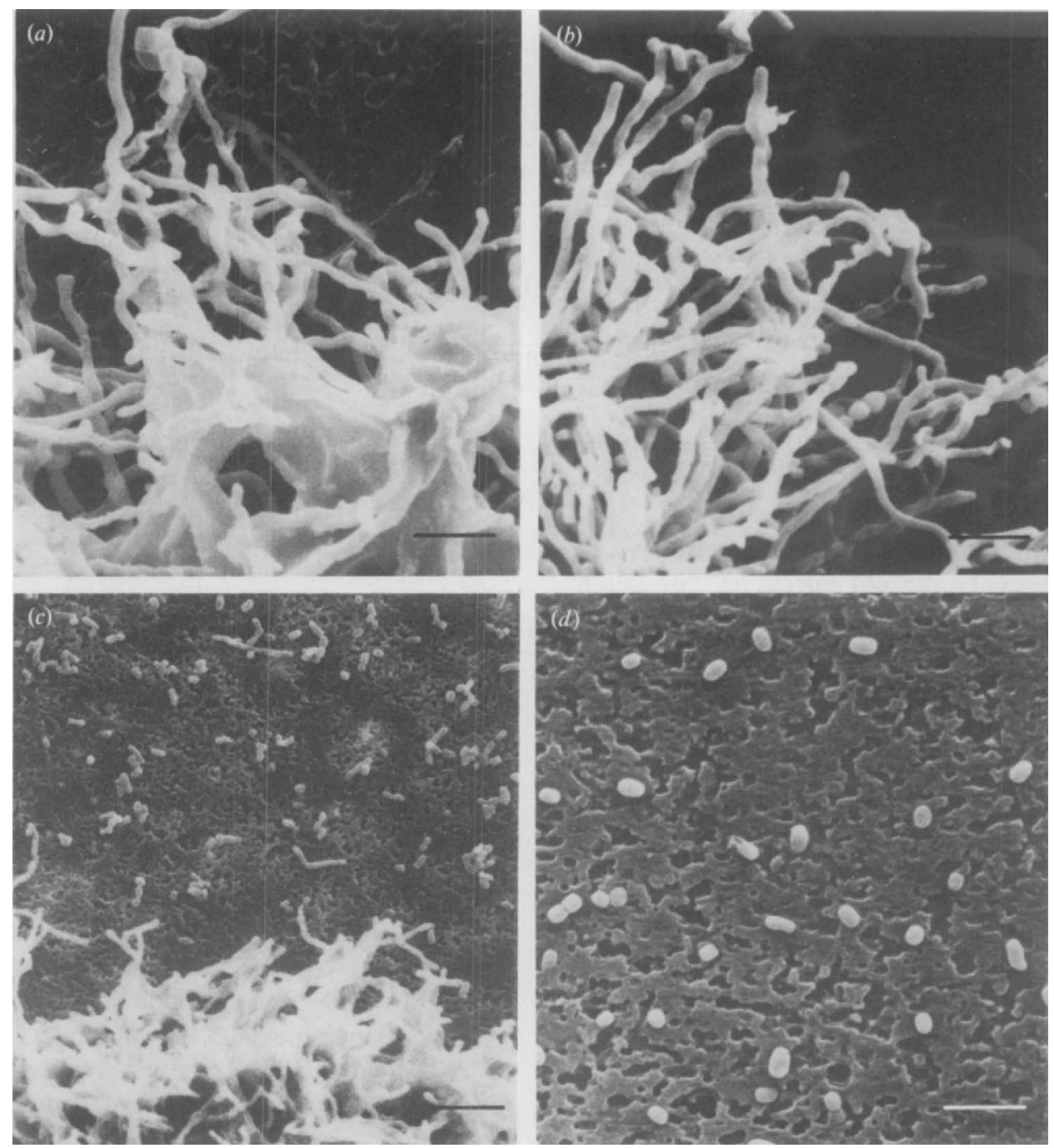

Fig. 3. Electron micrographs of $S$. venezuelae ISP5230 in LS medium with galactose $(3 \%)$ and ammonium sulphate $\left(2 \mathrm{~g}^{-1}\right)$. Samples removed on days $1,2,3$ and 5 are identified as $(a)-(d)$. Bars, $4 \mu \mathrm{m}(a, b, d) ; 10 \mu \mathrm{m}(c)$.

\section{Electron microscopy}

Cell material from cultures of $S$. venezuelae in LS medium with $0.2 \%$ ammonium sulphate and either $3 \%$ starch or $3 \%$ galactose was examined at daily intervals during a $5 \mathrm{~d}$ growth period. In cultures containing starch, little or no segmentation of mycelium into spores could be detected with a scanning electron microscope (Fig. 2). Cultures in the galactose-containing medium initially showed a progressive increase in the number of spore chains present (Fig. $3 a, b$ ) and subsequently contained large numbers of free spores (Fig. $3 c, d$ ). This contrasted with the absence of free spores at comparable times in the starch cultures (Fig. $2 c, d$ and other observations at lower magnification).

\section{Hypersporulation mutants}

When the effect of $3 \%$ glucose on sporulation of $S$. venezuelae ISP5320 in LS medium with a variety of nitrogen sources was examined, cultures containing ammonium sulphate, asparagine, Casamino acids or alanine, each providing $30 \mathrm{~mm}$-nitrogen, produced essentially no spores. Growth was poor in all of these media; the cultures rapidly accumulated acid(s) which, by day 3 , had lowered the broth $\mathrm{pH}$ values to $4 \cdot 6-5 \cdot 1$, despite the presence of $0.1 \mathrm{M}$-MOPS buffer, and had prevented further development. Suppression of sporulation by glucose might, therefore, be attributed to the physiological effects of this carbon source on growth rather than to its ability to control gene expression. 
Table 6. Growth of S. venezuelae strains ISP5230 and VS601 in LS medium with glucose or galactose

Cultures were incubated in LS medium supplemented with $0.4 \%$ Casamino acids and $3 \%$ glucose or galactose. The $\mathrm{OD}_{640}$ after inoculation was $1 \cdot 0$.

\begin{tabular}{|c|c|c|c|c|c|c|}
\hline \multirow[b]{2}{*}{ Strain } & \multicolumn{2}{|c|}{$\begin{array}{c}\text { Maximum biomass } \\
\left(\mathrm{OD}_{640}\right)\end{array}$} & \multicolumn{2}{|c|}{$\begin{array}{l}\text { Maximum rate of } \\
\text { sugar uptake } \\
\left(\mathrm{mg} \mathrm{l}^{-1} \mathrm{~h}^{-1}\right)\end{array}$} & \multicolumn{2}{|c|}{$\begin{array}{l}\text { Broth pH at growth } \\
\text { maximum }\end{array}$} \\
\hline & Glucose & Galactose & Glucose & Galactose & Glucose & Galactose \\
\hline ISP5230 & $2 \cdot 6$ & $4 \cdot 0$ & 800 & 458 & $5 \cdot 1$ & 7.0 \\
\hline VS601 & $4 \cdot 5$ & $1 \cdot 3$ & 416 & 0 & $6 \cdot 2$ & $7 \cdot 1$ \\
\hline
\end{tabular}

To investigate whether reduced acid production would eliminate the suppressive effect of glucose on sporulation in shaken cultures, we examined the properties of a hypersporulating mutant, strain VS601 (dev-2). This strain showed faster sporulation on both MYM and GYM agar than the wild-type or strain VS258 ( $p d x-4$ $c m l-12)$, the wild-type derivative in which the dev-2 mutation occurred, both of which required $48 \mathrm{~h}$ for sporulation on MYM agar and were very slow to form spores on GYM agar.

When the effect of $3 \%$ glucose as a carbon source in LS medium was examined, shaken cultures of strain VS601 containing Casamino acids, alanine or asparagine as the nitrogen source grew faster and produced more biomass than did the wild-type. The pH values in VS601 cultures were also higher (5.8-6.2 by day 3$)$ than those of ISP5230 and analysis of the cultures given Casamino acids showed that VS601 consumed glucose more slowly (Table 6).

In the medium with asparagine, strain VS601 formed some spores $(20 \%)$, but, like the wild-type failed to sporulate with alanine or Casamino acids. In LS medium containing maltose-ammonium sulphate or starchammonium sulphate, VS601 showed slightly increased sporulation compared to the wild-type (52\% versus $23 \%$ and $59 \%$ versus $12 \%$, respectively). Since VS601 could not assimilate galactose (Table 6), its sporulation characteristics on this carbon source could not be examined.

\section{Effect of decoyinine}

No differences in ability to form spores were observed when sporulating patches of $S$. venezuelae ISP5230 grown on MYM agar were replicated to GYM agar containing decoyinine at $0.005,0.025,0.05,0 \cdot 10,0.25$ or $0.5 \mathrm{~mm}$. That the drug was taken up by the mycelium was indicated by the inhibition of growth at 0.25 and $0.5 \mathrm{~mm}$.

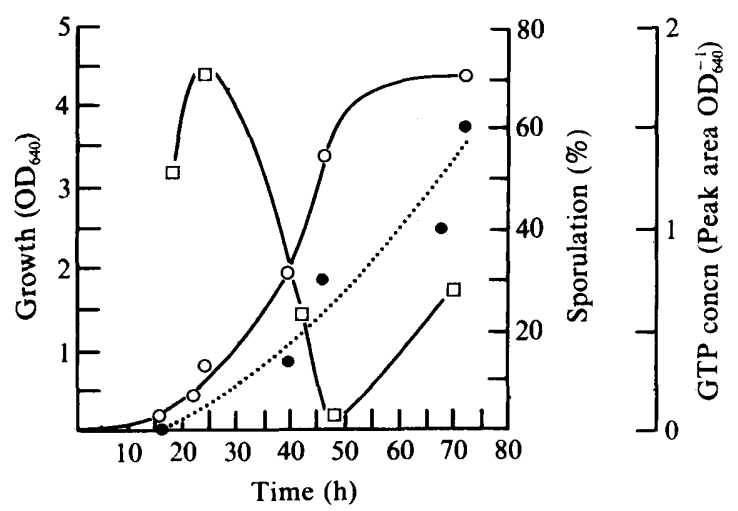

Fig. 4. Growth, sporulation and intracellular GTP concentration in cultures of $S$. venezuelae ISP5230 in LS medium containing 3\% galactose and 15 mm-ammonium sulphate: $O$, Growth; percentage sporulation; $\square$, GTP concentration measured as the area under the HPLC peak corresponding to GTP divided by the $\mathrm{OD}_{640}$ of the culture at that time.

When decoyinine was added at $0.05 \mathrm{mM}$ to LS medium supplemented with $3 \%$ starch and $0.2 \%$ ammonium sulphate, a slight increase in sporulation was observed

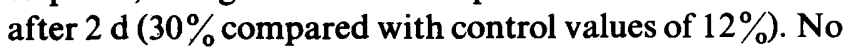
effect was found with higher concentrations of decoyinine.

Whereas strain ISP5230 formed abundant spores on starch-yeast extract sporulation agar, addition of $1 \%$ peptone suppressed sporulation. Decoyinine at 0.025 , $0.05,0.10$ or $0.25 \mathrm{~mm}$ did not reverse this suppression. Adding decoyinine ( $0.05,0 \cdot 10$ or $2 \mathrm{mM})$ to liquid cultures after $24 \mathrm{~h}$ growth in LS medium containing $3 \%$ galactose and $1.0 \%$ Casamino acids also failed to promote spore formation.

A drop in the intracellular GTP pool before the onset of sporulation was noted in shaken cultures containing $3 \%$ galactose and $0 \cdot 2 \%$ ammonium sulphate (Fig. 4).

\section{Discussion}

Spores from submerged or agar cultures of $S$. venezuelae resembled the aerial and submerged spores of $S$. viridochromogenes and $S$. coelicolor (Koepsel \& Ensign, 1984) in that, unlike vegetative mycelium, they were resistant to lysozyme digestion and sonic disruption. Kendrick \& Ensign (1983) showed that the aerial and submerged spores of Streptomyces species may differ in their resistance to harsh treatments. For example, although both aerial and submerged spores of $S$. griseus resisted sonication, only aerial spores resisted lysozyme treatment. Transmission electron micrographs suggested that the lysozyme sensitivity was due to the thinner walls of the submerged spores. The response of Streptomyces 
spores and hyphae to desiccation has not been reported elsewhere.

Carbon and nitrogen combinations that supported good growth did not necessarily inhibit sporulation. Conversely, those that supported poor growth did not necessarily promote extensive sporulation, indicating that morphological differentiation of $S$. venezuelae ISP5230 is not simply a response to unfavourable growth conditions. Of the six carbon sources tested for their ability to support sporulation, galactose was the most suitable and gave similar results at $3 \%$ or $5 \%$ concentration. Substantial differences were observed in the extent of sporulation with each compound, suggesting that carbon catabolism has a strong influence on the development process. Cultures supplied with galactose sporulated in media containing a variety of nitrogenous substances. Previous studies have established that at $3 \%$ initial concentration in the medium, the carbon source remains in excess throughout growth if the initial nitrogen concentration is limited to $30 \mathrm{~mm}$ (Shapiro \& Vining, 1983). The suppression of sporulation observed when the concentration of Casamino acids or asparagine in the medium was increased suggests that spores are formed abundantly only under nitrogen-limited conditions. A similar suppressive effect of increasing concentrations of Casamino acids on sporulation of S. griseus was reported by Ochi (1987).

Very low levels of sporulation were seen with cultures growing on glucose, a substrate that has been shown to suppress sporulation in other studies (Kendrick \& Ensign, 1983; Koepsel \& Ensign, 1984). Wild-type $S$. venezuelae accumulates large quantities of oxo-acids while growing in glucose (Ahmed \& Vining, 1984). Although this may contribute to the inability of glucose to support sporulation, results obtained with the mutant strain (VS601 (dev-2), which removed glucose more slowly from the medium, accumulated less acid, but showed only small increases in sporulation compared to the wild-type in glucose-containing media, suggest that the suppressive effect of glucose is not merely a secondary result of acid accumulation.

The ability of strain VS601 to sporulate on GYM agar but not in glucose-supplemented LS medium demonstrates that growth on agar media is not always comparable to growth in liquid cultures, and exposes the culture to different physiological effects which in time influence developmental processes. A similar physiological response may account for the hypersporulation phenotype of some $S$. venezuelae mutants. Strain VS601 appears to be altered in its ability to assimilate sugars. Further studies will attempt to define this lesion and relate it to the increased ability of the mutant to sporulate. Daza et al. (1988) reported submerged sporulation of several streptomycete species when phosphate is depleted in the medium. Since the LS medium used in our experiments contained a high level of phosphate, it is apparent that an excess of this nutrient does not on its own inhibit sporulation in $S$. venezuelae ISP5230. This emphasizes the diversity of cultural conditions now reported to promote submerged sporulation in different species of streptomycetes.

The failure of decoyinine to promote sporulation of $S$. venezuelae ISP5230 on agar and the weak effect obtained in a liquid medium contrasts with the induction of sporulation by decoyinine at $0.5-2 \mathrm{~mm}$ in cultures of $S$. griseus growing in rich media (Ochi, 1987), and with the results obtained by Ochi (1986) with Streptomyces MA 406-A-1. In the latter cultures also, the suppressive effect of $1 \%$ polypeptone on the formation of aerial mycelium could be reversed by decoyinine in concentrations ranging from 0.02 to $0.1 \mathrm{mM}$. The comparable effect of peptone on sporulation of $S$. venezuelae ISP5230 was not reversed by decoyinine. Consistent with the observations of Ochi, however, cultures of $S$. venezuelae ISP5230 growing in LS medium containing galactose and ammonium sulphate showed a sharp drop in the intracellular GTP level near the end of active growth when spores were being formed rapidly. It is possible that in this species the decline in GTP level is not causally related to the onset of sporulation, or, alternatively, that additional metabolic conditions have to be met before the decrease in GTP can function as a sporulation trigger.

We thank L. Maillet and M. Primrose for assistance with electron microscopy and photography, respectively and J. E. Grady (Upjohn Co., Kalamazoo, MI, USA) for a sample of decoyinine.

\section{References}

Ahmed, Z. U., Shapiro, S. \& Vining, L. C. (1984). Excretion of $\alpha$-keto acids by strains of Streptomyces venezuelae. Canadian Journal of Microbiology 30, 1014-1021.

Chatterjee, S., Vining, L. C. \& Westlake, D. W. S. (1983). Nutritional requirements for chloramphenicol biosynthesis in Streptomyces venezuelae. Canadian Journal of Microbiology 29, 247253.

Daza, A., Martin, J. F. \& Gil, J. A. (1988). Sporulation of several species of Streptomyces in submerged cultures. In Abstracts of the Seventh International Symposium on Biology of Actinomycetes (Tokyo, May 22-26, 1988), p. 108.

Doull, J. L., Vats, S., Chaliciopoulos, M., Stuttard, C., Wong, K. \& VINING, L. C. (1986). Conjugational fertility and location of chloramphenicol biosynthesis genes on the chromosomal linkage map of Streptomyces venezuelae. Journal of General Microbiology 132, 1327-1338.

DuBowskI, K. M. (1962). o-Toluidine method for body-fluid glucose determination. Clinical Chemistry 8, 215-235.

HoPwOOD, D. A. (1967). Genetic analysis in microorganisms. Methods in Microbiology 7B, 29-159.

Huber, F. M., PiPer, R. L. \& MERTZ, F. P. (1987). Sporulation of Streptomyces roseosporus in submerged culture. Journal of Industrial Microbiology 2, 235-241.

KENDRICK, K. E. \& ENSIGN, J. C. (1983). Sporulation of Streptomyces griseus in submerged cultures. Journal of Bacteriology 155, 357-366. 
Kozpsel, R. \& Ensign, J. C. (1984). Microcycle sporulation of Streptomyces viridochromogenes. Archives of Microbiology 140, 9-14.

OCHI, K. (1986). A decrease in GTP content is associated with aerial mycelium formation in Streptomyces MA406-A-1. Journal of General Microbiology 132, 299-305.

OCHI, K. (1987). Changes in nucleotide pools during sporulation of Streptomyces griseus in submerged cultures. Journal of General Microbiology 133, 2787-2795.
ShAPIRO, S. \& Vining, L. C. (1983). Nitrogen metabolism and chloramphenicol production in Streptomyces venezuelae. Canadian Journal of Microbiology 29, 1706-1714.

STUTTARD, C. (1982). Temperate phages of Streptomyces venezuelae: lysogeny and host specificity shown by SV1 and SV2. Journal of General Microbiology 128, 1706-1714.

VATS, S. (1987). The fine structure mapping of chloramphenicol biosynthesis genes in Streptomyces venezuelae. $\mathrm{PhD}$ thesis, Dalhousie University, Canada. 